Jurnal Health Sains: p-ISSN: 2723-4339 e-ISSN: 2548-1398

Vol. 2, No. 3, Maret 2021

\title{
PERBANDINGAN HANDOVER MODEL SBAR DAN I-PASS TERHADAP INSIDEN KESELAMATAN PASIEN
}

Eka Puji Hastuti, Ida Faridah, Yati Afiyanti

Sekolah Tinggi Ilmu Kesehatan (STIKes) Yatsi Tangerang Banten, Indonesia

Email: pujisantosa.id@gmail.com, Ida.farida72@gmail.com, yatiafiyanti@yahoo.com

\begin{tabular}{ll}
\hline ARTIKEL INFO & ABSTRACT \\
\hline Tanggal diterima: 5 Maret 2021 & SBAR and I-PASS are nurse handover models, to ensure \\
Tanggal direvisi: 15 Maret 2021 & the continued continuity of patient care services safely \\
Tanggal disetujui: 25 Maret & and effectively. Handover is a vital activity of nurses when \\
2021 & not done properly will result in a patient safety incident. \\
\hline Keywords: & The model is already considered effective in improving \\
SBAR; I-PASS; patient safety & patient safety. The purpose of this paper is to determine \\
incidents & the effectiveness of the SBAR and I-PASS handover \\
& models on patient safety in hospitals. The method used is \\
& literature review, search articles using online database \\
& PubMed, google scholar, mendeley from 2015-2020, in \\
& English using the keyword SBAR or I-PASS or handover \\
& or patient safety. Article selection process using PRISMA \\
& flow diagram. The results of the study were found using \\
& handover models SBAR and I-PASS can improve the \\
& quality of communication between nurses which has an \\
& impact on improving patient safety. The conclusion is that \\
& there is no proven standard of best practice for \\
& communication to use at handover. The SBAR and I-PASS \\
& models are effective communication tools to improve \\
communication quality and improve patient safety.
\end{tabular}

\section{ABSTRAK}

SBAR dan I-PASS merupakan model handover perawat, hal tersebut untuk memastikan kelanjutan kelangsungan pelayanan perawatan pasien secara aman dan efektif. Handover merupakan kegiatan vital perawat bilamana tidak dilakukan dengan baik akan mengakibatkan terjadinya insiden keselamatan pasien. Model tersebut sudah dianggap efektif dalam meningkatkan keselamatan pasien. Tujuan penulisan ini untuk mengetahui keefektifan model handover SBAR dan I-PASS terhadap keselamatan pasien di rumah sakit. Metode yang digunakan adalah literatur review, pencarian artikel dengan menggunakan database online PubMed, google scholar, mendeley dari tahun 2015-2020, berbahasa Inggris dengan menggunakan kata kunci SBAR or IPASS or handover or patient safety. Proses seleksi artikel dengan menggunakan flow diagram PRISMA. Hasil telaah ditemukan dengan menggunakan model handover SBAR dan I-PASS dapat meningkatkan kualitas komunikasi antar perawat yang berdampak terhadap 
Kata Kunci:

SBAR; I-PASS; insiden keselamatan pasien meningkatkan keselamatan pasien. Kesimpulannya adalah belum ada standar praktik terbaik yang terbukti untuk digunakan komunikasi saat handover. Model SBAR dan IPASS merupakan alat komunikasi yang terbilang efektif untuk meningkatkan kualitas komunikasi dan meningkatkan keselamatan pasien.

Coresponden Author:

Email: pujisantosa.id@gmail.com Artikel dengan akses terbuka dibawah lisensi

\section{Pendahuluan}

Rumah sakit merupakan tempat memberikan jasa pelayanan selama 24 jam, perawat merupakan salah satu pelaku dari pemberi pelayanan, dalam bekerja perawat dibagi dalam 3 shift. Sebelum melakukan pertukaran shift perawat melakukan handover. Jadi handover merupakan kegiatan rutin yang dilakukan perawat untuk memastikan pelayanan berkesinambungan (Karmila, Handiyani, \& Adiningtyaswati, 2018), aman dan efektif (Slade, Murray, Pun, \& Eggins, 2019).

Handover adalah pelimpahan tanggungjawab atas perawatan pasien ke shift selanjutnya (Merten, Van Galen, \& Wagner, 2017). Oleh karena itu informasi yang disampaikan harus jelas, lengkap, akurat dan dipahami oleh penerima (Merten et al., 2017). Sehingga dapat meminimalkan diskontinuitas perawatan, kesalahan, bahaya terhadap pasien dan pasien akan merasa lebih puas (JCI, 2018).

Tetapi dalam kenyataannya $80 \%$ insiden keselamatan disebabkan karena kegagalan komunikasi perawat saat handover sebanyak 10-15\% (Galatzan \& Carrington, 2018), hal tersebut mengakibatkan LOS meningkat, keterlambatan pengobatan, kesalahan obat, pasien jatuh (D. Piper, Lea, Woods, \& Parker, 2018); (K. Piper, 2017) bahkan 250.000 kematian tiap tahun di Amerika karena kegagalan komunikasi (Parent et al., 2018). KPPRS melaporkan 877 kejadian karena komunikasi yang tidak efektif.

Komunikasi efektif merupakan kunci keselamatan pasien hal tersebut mendorong perawat untuk menggunakan komunikasi yang terstruktur (Alert, 2017) sehingga informasi yang disampaikan akan menimbulkan makna yang sama (Usher, Cronin, \& York, 2018). WHO telah merekomendasikan SBAR dan I-PASS dijadikan sebagai alat komunikasi yang terstruktur untuk meningkatkan kualitas komunikasi dan meningkatkan keselamatan pasien (Pino et al., 2019). Metode SBAR saat serah terima pasien dapat menurunkan angka insiden keselamatan pasien dari 31\% menjadi $11 \%$ (Stewart \& Hand, 2017) Menurut penelitian dari (Type \& Date, n.d.) mengemukakan bahwa dengan menggunakan metode I-PASS meningkatkan kualitas komunikasi perawat sebesar 41,7\%. Berdasarkan fenomena tersebut penulis tertarik untuk melakukan literatur review untuk mengetahui perbandingan model SBAR dan I-PASS terhadap keselamatan pasien.

\section{Metode Penelitian}

Metode yang digunakan adalah literatur review yang dilakukan dengan menganalisa artikel yang terkait. Pencarian artikel dengan menggunakan database online yaitu PUBMED, google scholar, Mendeley, kata kunci handover or SBAR or I-PASS or patient safety rentang waktu 2015-2020. 
Kriteria inklusi dan eksklusi dengan menggunakan kerangka PICO (pupulation, intervention, comparation, outcome). Kriteria inklusi yaitu artikel yang relevan dengan tujuan penelitian baik judul dan isinya, barbahasa Inggris, full text. Kriteria ekslusi adalah artikel dimana judul, isi serta struktur yang tidak sesuai dengan tujuan penelitian. Kajian literatur ini dengan menggunakan 10 jurnal yang dipublikasikan pada tahun 20152020 pemilihan artikel dilakukan dengan flow diagram PRISMA.

\section{Hasil dan Pembahasan}

Hasil penelitian 10 artikel yang dilakukan di Amerika dan Jerman pada perawat yang menggunakan model SBAR dan I-PASS di ruang emergency, intensive, anesthesi mempunyai dampak terhadap keselamatan pasien.

Tabel 1 Ringkasan Penelitian

\begin{tabular}{|c|c|c|c|}
\hline No & Peneliti /judul & Sampel & Hasil \\
\hline 1 & $\begin{array}{l}\text { Amy J Starmer, Kumiko O } \\
\text { Schnock, } 2017 \\
\text { "effects of the I-PASS } \\
\text { nursing handoff bundle on } \\
\text { communication quality and } \\
\text { workflow" }\end{array}$ & Perawat ICU & $\begin{array}{l}\text { I-PASS } \\
\text { menurunkan } \\
\text { interupsi } \\
(27 \%) \\
\text { meningkatkan } \\
\text { kelengkapan } \\
\text { data }(32 \%) \\
\end{array}$ \\
\hline 2 & $\begin{array}{l}\text { Matthew Mardis, Joshua } \\
\text { Davis, Branden } \\
\text { Benningfield, } 2015 \\
\text { "shift to shift handoff } \\
\text { effects on patient safety } \\
\text { and outcomes" }\end{array}$ & $\begin{array}{l}\text { Perawat di } \\
\text { ruang rawat } \\
\text { inap }\end{array}$ & $\begin{array}{l}\text { SBAR, I- } \\
\text { PASS } \\
\text { meningkatkan } \\
\text { keselamatan } \\
\text { pasien }(29 \%)\end{array}$ \\
\hline 3 & $\begin{array}{l}\text { Martin Muller, Jonas } \\
\text { Jurgens, } 2018 \\
\text { "impact of the } \\
\text { communication and patient } \\
\text { handoff tool SBAR on } \\
\text { patient safety" }\end{array}$ & $\begin{array}{l}\text { perawat di } \\
\text { ruang rawat } \\
\text { inap }\end{array}$ & $\begin{array}{l}\text { SBAR } \\
\text { meningkatkan } \\
\text { kualitas } \\
\text { komunikasi }\end{array}$ \\
\hline 4 & $\begin{array}{l}\text { Darcy Alimenti, Sarah } \\
\text { Buydos, } 2019 \\
\text { "improving perceptions of } \\
\text { patient safety through } \\
\text { stabdardizing handoff from } \\
\text { the emergencydepartement } \\
\text { to the inpatient setting }\end{array}$ & $\begin{array}{l}\text { Perawat } \\
\text { emergency }\end{array}$ & $\begin{array}{l}\text { Komunikasi } \\
\text { efektif } \\
\text { dengan } \\
\text { SBAR } \\
\text { meningkatkan } \\
\text { kontinuitas } \\
\text { pelayanan } \\
\text { dan } \\
\text { keselamatan } \\
\text { pasien } \\
(80,9 \%) \\
\end{array}$ \\
\hline 5 & $\begin{array}{l}\text { Reed S. Halterman } \\
\text { Mohamed Gaber, } 2019 \\
\text { "use of a checklist for the } \\
\text { post anesthesia care unit } \\
\text { patient handoff" }\end{array}$ & $\begin{array}{l}\text { Perawat } \\
\text { anesthesi }\end{array}$ & $\begin{array}{l}\text { Formulir } \\
\text { handoff } \\
\text { ceklist } \\
\text { menurunkan } \\
\text { kelalaian } \\
\text { perawat } \\
(19,2 \%) \\
\end{array}$ \\
\hline 6 & $\begin{array}{l}\text { Zou, Xiang Jun, and Yin } \\
\text { Ping Zhang, } 2016 \\
\text { "Rates of Nursing Errors }\end{array}$ & $\begin{array}{l}\text { Perawat di } \\
\text { rawar inap }\end{array}$ & $\begin{array}{l}\text { Formulir } \\
\text { handover } \\
\text { meningkatak }\end{array}$ \\
\hline
\end{tabular}

\begin{tabular}{|c|c|c|c|}
\hline & $\begin{array}{l}\text { and Handoffs-Related } \\
\text { Errors in a Medical Unit } \\
\text { Following Implementation } \\
\text { of a Standardized Nursing } \\
\text { Handoff Form" }\end{array}$ & & $\begin{array}{l}\text { efektifitas } \\
\text { dan } \\
\text { mengurangi } \\
\text { kesalahan }\end{array}$ \\
\hline 7 & $\begin{array}{l}\text { M.Skaret, T. Weaver, R. } \\
\text { Humes et al, } 2019 \\
\text { "Automation of the I-PASS } \\
\text { tool to improve Transition } \\
\text { of care" }\end{array}$ & $\begin{array}{l}\text { Perawat } \\
\text { dirawat inap }\end{array}$ & $\begin{array}{l}\text { Format } \\
\text { elektronik I- } \\
\text { PASS } \\
\text { mengurangi } \\
\text { kesalahan } \\
(45,6 \%) \\
\end{array}$ \\
\hline 8 & $\begin{array}{l}\text { H. Hughes, J. Serwint, J. O } \\
\text { Toole et al, } 2019 \\
\text { "I-PASS adherence and } \\
\text { implications for future } \\
\text { Handoff Training", }\end{array}$ & $\begin{array}{l}\text { Perawat } \\
\text { pasca sarjana }\end{array}$ & $\begin{array}{l}\text { I-PASS } \\
\text { meningkatkan } \\
\text { komunikasi } \\
\text { pada pasien } \\
\text { yang } \\
\text { komplek } \\
\text { (sintesis) }\end{array}$ \\
\hline 9 & $\begin{array}{l}\text { S. Malfait, A. Van Hecke, } \\
\text { W. Van Biesen et al, } 2018 \\
\text { "Do Bedside Handovers } \\
\text { Reduce Handover } \\
\text { Duration? An } \\
\text { Observational Study With } \\
\text { Implications for Evidence- } \\
\text { Based Practice" }\end{array}$ & $\begin{array}{l}\text { Perawat } \\
\text { rawat inap }\end{array}$ & $\begin{array}{l}\text { Form serah } \\
\text { terima model } \\
\text { SBAR } \\
\text { meningkatkan } \\
\text { kualitas } \\
\text { handover }\end{array}$ \\
\hline 10 & $\begin{array}{l}\text { J. Walia, Z. Qayumi, } \\
\text { N.Khawar et al } 2016 \\
\text { "Physician Transition of } \\
\text { Care: Benefits of I-PASS } \\
\text { and an Electronic Handoff } \\
\text { System in a Community } \\
\text { Pediatric } \quad \text { Residency } \\
\text { Program" }\end{array}$ & $\begin{array}{l}\text { Perawat di } \\
\text { ruang bayi } \\
\text { baru lahir } \\
\text { dan anak }\end{array}$ & $\begin{array}{l}\text { I-PASS } \\
\text { meningkatkan } \\
\text { kualitas } \\
\text { komunikasi } \\
\text { dan kualitas } \\
\text { handover }\end{array}$ \\
\hline
\end{tabular}

Hasil review 10 artikel tersebut didapatkan beberapa hal penting yaitu: komunikasi yang dilakukan perawat saat handover harus secara efektif dan terstruktur dengan model SBAR atau I-PASS untuk memastikan kelangsungan perawatan yang diberikan ke pasien secara aman dalam arti tidak menimbulkan cedera (pasien jatuh, terjadi decubitus, kesalahan obat), keterlambatan pengobatan, diskontinuitas perawatan yang menyebabkan bertambahnya hari rawat, bahkan bisa menyebabkan pasien meninggal.

\section{Komunikasi efektif dalam handover perawat.}

Handover merupakan wadah pertukaran informasi dan pelimpahan tanggung jawab perawat tentang status kesehatan, tindakan yang telah dilakukan, tindakan yang akan dilakukan selanjutnya sehingga pelayanan tetap diberikan secara aman dalam 24 jam (Galatzan \& Carrington, 2018), sehingga informasi yang disampaikan harus jelas, lengkap, 
sesuai perkembangan pasien, benar dipahami, persepsi yang sama dan tidak ambigu (Van Der Wulp, Poot, Nanayakkara, Loer, \& Wagner, 2019). Handover dapat dilakukan secara lisan atau tertulis dengan menggunakan paper base, handover elektronik dapat menurunkan waktu sebanyak $48,6 \%$ atau setara dari waktu 10,5 ke 5,4 menit (Sun, Shih, \& Cheng, 2018), disampaikan secara sistematis dan terorganisir (SARI, 2020) dalam waktu 5-15 menit (Bakon, Wirihana, Christensen, \& Craft, 2017). Handover dengan menggunakan formulir serah terima akan meningkatkan kualitas komunikasi yang berdampak terhadap kualitas handover tersebut serta dilakukan dengan melibatkan keluarga (Parlar Kilic, Ovayolu, Ovayolu, \& Hayrullah Ozturk, 2017).

Dalam kenyataan masih terdapat insiden keselamatan pasien karena kesalahan komunikasi perawat (JCI, 2018). Hal tersebut terjadi karena informasi yang diberikan tidak lengkap, tidak sesuai kondisi sebenarnya, komunikasi satu arah, interupsi, informasi terlalu panjang sehingga sulit dipahami, komunikasi tidak stertsruktur, tulisan tidak bisa dibaca dengan benar (Pino et al., 2019). Akibat komunikasi yang tidak baik tersebut akan mengakibatkan keterlambatan pengobatan, terjadi komplikasi, terputusnya perawatan sehingga meningkatkan insiden keselamatan pasien (Streeter \& Harrington, 2017). Gangguan komunikas meningkatkan resiko terjadi kesalahan sebesar $12.7 \%$, keterlambatan pengobatan sebesar $90 \%$

Hal yang bisa dilakukan untuk mengatasi hambatan komunikasi diantaranya dengan melakukan handover secara tatap muka, dilakukan ditempat khusus dan diupayakan tertutup, dokumentasi dilakukan secara elektronik, adanya pertanyaan untuk klarifikasi informasi (Habicht et al., 2016). Tingkat kepatuhan perawat untuk menggunakan komunikasi yang terstruktur dalam handover akan meningkatkan kualitas informasi sebesar 29\%-48\% (D. Piper et al., 2018) dan meningkatkan kualitas handover yang mempunyai dampak terhadap keselamatan pasien (Clanton, Clark, Loggins, \& Herron, 2018); (Malfait, Eeckloo, Van Biesen, \& Van Hecke, 2019); (Streeter \& Harrington, 2017); (Dhamanti, Leggat, Barraclough, \& Tjahjono, 2019); (Merten et al., 2017).

\section{Handover Model SBAR terhadap Keselamatan Pasien}

SBAR terdiri dari Situation

Bacground Assessment

Recomenmendation, alat komunikasi yang dikembangkan oleh angkatan laut AS untuk mengatur informasi kedalam pola yang logis dan mudah diingat, mempercepat proses handover dan mengurangi kesalahan (Bukoh \& Siah, 2020); (Müller et al., 2018). Dengan format SBAR, diagnosis pasien bisa dijelaskan kedalam situation, penjelasan singkat tentang kondisi pasien saat ini, riwayat medis, riwayat pembedahan, hasil pemeriksaan fisik termasuk tanda vital terbaru, skor peringkat intensitas nyeri, akses IV line bisa dicantumkan ke dalam background, penjelasan tentang masalah pasien secara keseluruhan dijelaskan dalam assessment dan rencana yang akan dilakukan pada shift senjutnya untuk mengatasi masalah pasien dijelaskan dalam recommendation (Malfait et al., 2019). SBAR dapat dipergunakan untuk menyampaikan informasi baik lisan atau tertulis dan informasi menjadi leih terarah (Shahid \& Thomas, 2018), meningkatkan kepercayaan, mempersingkat waktu, alur kerja dan kerjasama meningkat (Schmidt, 
Kocher, Mahendran, \& Denecke, 2019); (Zavala \& Shaffer, 2011); (Ting, Peng, Lin, \& Hsiao, 2017). Daftar tilik handover akan meningkatkan daya ingat perawat sehingga menghindari data yang tertinggal (Randmaa, Swenne, Mårtensson, Högberg, \& Engström, 2016) data yang diberikan lengkap dan meningkatkan kualitas informasi (Ruhomauly et al., 2019); (Shahid \& Thomas, 2018). Informasi yang sampaikan harus didokumentasikan dengan baik (Palareti et al., 2016); (Robinson, 2016); (Groves, Manges, \& Scott-Cawiezell, 2016) dalam format SOAP (Shahid \& Thomas, 2018). Dengan SBAR kegagalan komunikasi dapat dikurangi dengan demikian akan dapat memastikan keselamatan pasien (Achrekar et al., 2016). Sehingga SBAR sebagai alat komunikasi yang meningkatkan kualitas pelayanan yang berbasis bukti (Cross, Considine, \& Currey, 2019); (Rosenbluth et al., 2018).

\section{Handover Model I-PASS terhadap} Keselamatan Pasien.

I-PASS sebagai alat handover perawat di rumah sakit pediatrik di Boston dengan populasi pasien yang rentan (Clements, 2017). Kerangka I-PASS terdiri dari Ilness severity (tingkat keparahan penyakit): dijelaskan tentang keadaan pasien dalam kondisi stabil atau tidak stabil Patient summary (ringkasan pasien): komponen ringkasan pasien lebih ditekankan dengan kelengkapan (jelas dan spesifik) dibanding keringkasan, Action list (daftar tindakan) yang akan dilakukan, Situation awareness and contingency planning (keadaan situasional dan perencanaan): data tentang kondisi yang akan diprediksikan bisa terjadi ke pasien dan tindakan yang bisa dilakukan bila terjadi, Syntesis by receiver (sintesis oleh penerima): pernyataan kembali informasi untuk memastikan keakurasi informasi, I-
PASS merupakan salah satu dari sedikit intervensi keselamatan pasien yang terbukti dalam mengurangi cedera yang dapat dicegah (Starmer et al., 2017). Keberhasilan model I-PASS dipengaruhi oleh kondisi pasien, faktor individu atau tim dalam hal ini adalah perawat; perawat senior yang mampu berfikir kritis dan memahami konteks keselamatan pasien (Coffey et al., 2017).

Kerangka I-PASS fleksibel sehingga bisa digunakan diberbagai konteks klinis diantaranya adalah bangsal anak di RS di Amerika Serikat, I-PASS selain digunakan oleh perawat saat handover bisa juga digunakan oleh dokter saat handover, dengan menggunakan dokumentasi secara elektronik (Skaret et al., 2019) terbukti meningkatkan kinerja, mengurangi kesalahan (Blazin, SitthiAmorn, Hoffman, \& Burlison, 2020). Menurut penelitian dari (Lam, Arora, \& Menchine, 2016) pengunaan I-PASS yang dimodifikasi secara singkat dan jelas di ruang emergency dapat mengurangi kejadian kesalahan obat saat pergantian shift. Selain itu model I-PASS bisa digunakan di bangsal psikiatri dengan menggunakan daftar ceklist tambahan yang berisikan riwayat perilaku, obat-obat yang harus dihindari, obat yang perlu diperlukan untuk nyeri, tidur dan kecemasan dapat memperbaiki kualitas komunikasi, menurunkan kejadian kesalahan obat serta memperbaiki alur kerja perawat (Bowes, Santiago, Hepps, Hershey, \& Yu, 2018). Oleh karena itu model I-PASS mempunyai dampak terhadap keselamatan pasien dan mampu mengurangi peluang kesalahan (Bigani \& Correia, 2018); (Groves et al., 2016).

I-PASS berfokus pada stratifikasi resiko, mempromosikan deteksi dini pasien yang kemungkinan besar akan mengalami dekompensasi dan mendorong 
penyedia layanan untuk membuat rencana darurat jika kondisi pasien memburuk, hal tersebut meningkatkan konsentrasi perawat dan perawat lebih memahami dampak dan bahaya klinis (Sheth et al., 2016); (Clanton et al., 2018); (Starmer et al., 2017). Pemikiran kritis perawat tentang proses memberikan asuhan secara berkualitas yang didukung dengan lingkungan kerja yang memfasilitasi kegiatan perawat dalam hal ini atasan sangat berpengaruh, perawat dapat memberikan pelayanan berkualitas sehingga komplikasi pasien bisa dicegah, intervensi keperawatan akan diberikan secara tepat yang berpengaruh terhadap tingkat kesembuhan pasien sehingga mengurangi hari rawat pasien di rumah sakit (Eltaybani, Noguchi-Watanabe, Igarashi, Saito, \& Yamamoto-Mitani, 2018). Keuntungan yang didapat dari tingkat kepatuhan perawat menggunakan bundle I-PASS secara konsisten (Hughes, Serwint, O’Toole, Spector, \& Ngo, 2019) adalah menurunkan tingkat interupsi, menurunkan waktu proses handover (Rosenbluth et al., 2018) sehingga perawat mempunyai waktu lebih untuk berinteraksi dengan pasien dan hal tersebut meningkatkan kepuasan pasien dan keluarga, keluarga mendapatkan informasi dengan jelas dan lengkap, keluarga mempunyai kesempatan untuk bertanya (Sheth et al., 2016). I-PASS meningkatkan kualitas informasi menentukan kualitas handover perawat yang akan menentukan pelayanan secara aman dapat diberikan ke pasien yang berdampak terhadap keselamatan pasien di rumah sakit (Graan, Botti, Wood, \& Redley, 2016); (Usher et al., 2018); (Davis et al., 2017).

\section{Kesimpulan}

Berdasarkan hasil telaah yang dilakukan pada 10 artikel maka disimpulkan bahwa informasi merupakan kunci utama dari insiden keselamatan pasien. Oleh karena itu sebagai perawat kita meningkatkan komunikasi dengan menggunakan model yang terstruktur sehingga meningkatkan keselamatan pasien. Saat ini belum ada standar praktik terbaik yang terbukti untuk digunakan komunikasi saat handover. Model SBAR dan I-PASS merupakan alat komunikasi yang terbilang efektif untuk meningkatkan kualitas komunikasi dan meningkatkan keselamatan pasien.

\section{BIBLIOGRAFI}

Achrekar, M., Murthy, V., Kanan, S., Shetty, R., Nair, M., \& Khattry, N. (2016). Introduction Of Situation, Background, Assessment, Recommendation Into Nursing Practice: A Prospective Study. Asia-Pacific Journal of Oncology Nursing, 3(1), 45.

Alert, S. E. (2017). Inadequate Hand-Off Communication. Sentinel Event Alert, $58,1-6$.

Bakon, S., Wirihana, L., Christensen, M., \& Craft, J. (2017). Nursing Handovers: An Integrative Review Of The Different Models And Processes Available. International Journal of Nursing Practice, 23(2), 1-8.

Bigani, D. K., \& Correia, A. M. (2018). On The Same Page: Nurse, Patient, And Family Perceptions Of Change-Of-Shift Bedside Report. Journal Of Pediatric Nursing, 41, 84-89.

Blazin, L. J., Sitthi-Amorn, J., Hoffman, J. M., \& Burlison, J. D. (2020). Improving Patient Handoffs And Transitions Through Adaptation And Implementation Of I-Pass Across Multiple Handoff Settings. Pediatric Quality \& Safety, 5(4), E323.

Bowes, M. R., Santiago, P. N., Hepps, J. H., Hershey, B. R., \& Yu, C. E. (2018). Using I-Pass In Psychiatry Residency 
Transitions Of Care. Academic Psychiatry, 42(4), 534-537.

Bukoh, M. X., \& Siah, C. R. (2020). A Systematic Review On The Structured Handover Interventions Between Nurses In Improving Patient Safety Outcomes. Journal Of Nursing Management, 28(3), 744-755.

Clanton, J., Clark, M., Loggins, W., \& Herron, R. (2018). Effective Handoff Communication. Vignettes In Patient Safety - Volume 2.

Clements, B. K. (2017). High-Reliability And The I-Pass Communication Tool.

Coffey, M., Thomson, K., Li, S.-A., Bismilla, Z., Starmer, A. J., O'toole, J. K., ... Yu, C. E. (2017). Resident Experiences With Implementation Of The I-Pass Handoff Bundle. Journal Of Graduate Medical Education, 9(3), 313.

Cross, R., Considine, J., \& Currey, J. (2019). Nursing Handover Of Vital Signs At The Transition Of Care From The Emergency Department To The Inpatient Ward: An Integrative Review. Journal Of Clinical Nursing, 28(5-6), 1010-1021.।

Davis, J., Roach, C., Elliott, C., Mardis, M., Justice, E. M., \& Riesenberg, L. A. (2017). Feedback And Assessment Tools For Handoffs: A Systematic Review. Journal Of Graduate Medical Education, 9(1), 18-32.

Dhamanti, I., Leggat, S., Barraclough, S., \& Tjahjono, B. (2019). Patient Safety Incident Reporting In Indonesia: An Analysis Using World Health Organization Characteristics For Successful Reporting. Risk Management And Healthcare Policy, 12, 331-338.

Eltaybani, S., Noguchi-Watanabe, M., Igarashi, A., Saito, Y., \& YamamotoMitani, N. (2018). Factors Related To Intention To Stay In The Current Workplace Among Long-Term Care Nurses: A Nationwide Survey.
International Journal of Nursing Studies, 80(August 2017), 118-127.

Galatzan, B. J., \& Carrington, J. M. (2018). Exploring The State Of The Science Of The Nursing Hand-Off Communication. Cin - Computers Informatics Nursing, 36(10), 484-493.

Graan, S. M., Botti, M., Wood, B., \& Redley, B. (2016). Nursing Handover From Icu To Cardiac Ward: Standardised Tools To Reduce Safety Risks. Australian Critical Care, 29(3), 165-171.

Groves, P. S., Manges, K. A., \& ScottCawiezell, J. (2016). Handing Off Safety At The Bedside. Clinical Nursing Research, 25(5), 473-493.

Habicht, R., Block, L., Silva, K. N., Oliver, N., Wu, A., \& Feldman, L. (2016). Assessing Intern Handover Processes. Clinical Teacher, 13(3), 187-191.

Hughes, H. K., Serwint, J. R., O'toole, J. K., Spector, N. D., \& Ngo, T. L. (2019). IPass Adherence And Implications For Future Handoff Training. Journal of Graduate Medical Education, 11(3), 301-306.

Jci. (2018). Communicating Clearly And Effectively To Patients How To Overcome Common Communication Challenges In Health Care. 11. Retrieved From Http://Www.Jointcommissioninternatio nal.Org.

Karmila, R., Handiyani, H., \& Adiningtyaswati, E. (2018). Description Of Nursing Shift Handover Implementation In One Of Provincial Public Hospitals In Dki Jakarta Province. Int J Med Pharm Res, 8, 3948.

Lam, C. N., Arora, S., \& Menchine, M. (2016). Increased 30-Day Emergency Department Revisits Among Homeless Patients With Mental Health Conditions. Western Journal of Emergency Medicine, 17(5), 607. 
Malfait, S., Eeckloo, K., Van Biesen, W., \& Van Hecke, A. (2019). The Effectiveness Of Bedside Handovers: A Multilevel, Longitudinal Study Of Effects On Nurses And Patients. Journal Of Advanced Nursing, 75(8), 16901701.

Merten, H., Van Galen, L. S., \& Wagner, C. (2017). Safe Handover. Bmj (Online), $359,1-5$.

Müller, M., Jürgens, J., Redaèlli, M., Klingberg, K., Hautz, W. E., \& Stock, S. (2018). Impact Of The Communication And Patient Hand-Off Tool Sbar On Patient Safety: A Systematic Review.

Palareti, G., Legnani, C., Cosmi, B., Antonucci, E., Erba, N., Poli, D., ... De Micheli, V. (2016). Comparison Between Different D-D Imer Cutoff Values To Assess The Individual Risk Of Recurrent Venous Thromboembolism: Analysis Of Results Obtained In The Dulcis Study. International Journal of Laboratory Hematology, 38(1), 42-49.

Parent, B., Lagrone, L. N., Albirair, M. T., Serina, P. T., Keller, J. M., Cuschieri, J., ... Kritek, P. A. (2018). Effect Of Standardized Handoff Curriculum On Improved Clinician Preparedness In The Intensive Care Unit A Stepped-Wedge Cluster Randomized Clinical Trial. Jama Surgery, 153(5), 464-470.

Parlar Kilic, S., Ovayolu, N., Ovayolu, O., \& Hayrullah Ozturk, M. (2017). The Approaches And Attitudes Of Nurses On Clinical Handover. International Journal Of Caring Sciences, 10(1), 1136. Retrieved From Www.Internationaljournalofcaringscien ces.Org

Pino, F. A., Sam, K. J., Wood, S. L., Tafreshi, P. A., Parks, S. L., Bell, P. A., ... Peter, S. D. S. (2019). Increasing Compliance With A New Interunit Handoff Process: A Quality Improvement Project. Pediatric Quality \& Safety, 4(3).
Piper, D., Lea, J., Woods, C., \& Parker, V. (2018). The Impact Of Patient Safety Culture On Handover In Rural Health Facilities. Bmc Health Services Research, 18(1), 1-13.

Piper, K. (2017). Scaffolding Clinical Reasoning And Decision Making: Clinical Handover. (December), 11-13.

Randmaa, M., Swenne, C. L., Mårtensson, G., Högberg, H., \& Engström, M. (2016). Implementing Situation-BackgroundAssessment-Recommendation In An Anaesthetic Clinic And Subsequent Information Retention Among Receivers. European Journal Of Anaesthesiology, 33(3), 172-178.

Robinson, N. L. (2016). Promoting Patient Safety With Perioperative Hand-Off Communication. Journal Of Perianesthesia Nursing, 31(3), 245-253.

Rosenbluth, G., Destino, L. A., Starmer, A. J., Landrigan, C. P., Spector, N. D., Sectish, T. C., \& Committee, I.-P. C. (2018). I-Pass Handoff Program: Use Of A Campaign To Effect Transformational Change. Pediatric Quality \& Safety, 3(4), E088.

Ruhomauly, Z., Betts, K., Jayne-Coupe, K., Karanfilian, L., Szekely, M., Relwani, A., ... Jaffry, Z. (2019). Improving The Quality Of Handover: Implementing Sbar. Future Healthcare Journal, 6(Suppl 2), 54-54.

Sari, D. N. U. R. P. (2020). Perbandingan Handover Model Sbar Dan I-Pass Terhadap Insiden Keselamatan Pasien: Literatur Review. Jurnal Surya, 12(3), 82-90.

Schmidt, T., Kocher, D. R., Mahendran, P., \& Denecke, K. (2019). Dynamic Pocket Card For Implementing Isbar In Shift Handover Communication. Studies In Health Technology And Informatics, 267, 224-229.

Shahid, S., \& Thomas, S. (2018). Situation, Background, Assessment, 
Recommendation

(Sbar)

Communication Tool For Handoff In Health Care - A Narrative Review. Safety In Health, 4(1), 1-9.

Sheth, S., Mccarthy, E., Kipps, A. K., Wood, M., Roth, S. J., Sharek, P. J., \& Shin, A. Y. (2016). Changes In Efficiency And Safety Culture After Integration Of An I-Pass-Supported Handoff Process. Pediatrics, 137(2).

Skaret, M. M., Weaver, T. D., Humes, R. J., Carbone, T. V., Grasso, I. A., \& Kumar, H. (2019). Automation Of The I-Pass Tool To Improve Transitions Of Care. Journal For Healthcare Quality, 41(5), 274-280.

Slade, D., Murray, K. A., Pun, J. K. H., \& Eggins, S. (2019). Nurses' Perceptions Of Mandatory Bedside Clinical Handovers: An Australian Hospital Study. Journal Of Nursing Management, 27(1), 161-171.

Starmer, A. J., Spector, N. D., West, D. C., Srivastava, R., Sectish, T. C., Landrigan, C. P., ... Allen, A. D. (2017).

Integrating Research, Quality Improvement, And Medical Education For Better Handoffs And Safer Care: Disseminating, Adapting, And Implementing The I-Pass Program. The Joint Commission Journal On Quality And Patient Safety, 43(7), 319-329.

Stewart, K. R., \& Hand, K. A. (2017). Sbar, Communication, And Patient Safety: An Integrated Literature Review. Medsurg Nursing, Vol. 26, Pp. 297-305. Anthony J. Jannetti Publications, Inc.

Streeter, A. R., \& Harrington, N. G. (2017). Nurse Handoff Communication. Seminars In Oncology Nursing, 33(5), 536-543.

Sun, Y.-K., Shih, W.-C., \& Cheng, K.-H. (2018). An Electronic Handover System
To Improve Information Transfer For Surgical Patients. Cin: Computers, Informatics, Nursing, 36(12), 610-614.

Ting, W.-H., Peng, F.-S., Lin, H.-H., \& Hsiao, S.-M. (2017). The Impact Of Situation-Background-AssessmentRecommendation (Sbar) On Safety Attitudes In The Obstetrics Department. Taiwanese Journal Of Obstetrics And Gynecology, 56(2), 171-174.

Type, I., \& Date, P. (N.D.). Interunit Implementation Of $A$ Standardized Nurse Handoff Method In Cardiac Surgery.

Usher, R., Cronin, S. N., \& York, N. L. (2018). Evaluating The Influence Of A Standardized Bedside Handoff Process In A Medical-Surgical Unit. Journal Of Continuing Education In Nursing, 49(4), 157-163.

Van Der Wulp, I., Poot, E. P., Nanayakkara, P. W. B., Loer, S. A., \& Wagner, C. (2019). Handover Structure And Quality In The Acute Medical Assessment Unit: A Prospective Observational Study. Journal Of Patient Safety, 15(3), 224229.

Zavala, S., \& Shaffer, C. (2011). Do Patients Understand Discharge Instructions? Journal Of Emergency Nursing, 37(2), 138-140. 